\title{
Insights into the Synergistic Effect of Fungi and Bacteria for Reactive Red Decolorization
}

\author{
Dandan Zhou, Xueying Zhang, Yilin Du, Shuangshi Dong, Zhengxue Xu, and Lei Yan \\ Key Lab of Groundwater Resources and Environment, Jilin University, Ministry of Education, Changchun 130021, China \\ Correspondence should be addressed to Shuangshi Dong; sdong@jlu.edu.cn
}

Received 29 May 2014; Accepted 3 July 2014; Published 10 August 2014

Academic Editor: Qingrui Zhang

Copyright (C) 2014 Dandan Zhou et al. This is an open access article distributed under the Creative Commons Attribution License, which permits unrestricted use, distribution, and reproduction in any medium, provided the original work is properly cited.

Bacterial contamination is a prevalent problem in fungal dye wastewater decolorization that prevents the development of this technology in practical engineering. New insight into the relationship between fungi and bacteria is given in terms of settleability, bioadsorption, and biodegradation, which all confirm their synergistic effect. Sterilization is implied to be not the only mechanism for fungi decolorization. When the fungi and bacteria isolated from the activated sludge were cocultured, fungi removed more than $70 \%$ of the reactive red through sole bioadsorption in $5 \mathrm{~min}$ and enhanced the settleability of the bacteria group from 7.7 to 18.4 in the aggregation index. Subsequently, the bacteria played a more significant role in dye biodegradation according to the ultravioletvisible spectrum analysis. They further enhanced the decolorization efficiency to over $80 \%$ when cocultured with fungi. Therefore, the advanced bioadsorption and settleability of fungi, combined with the good dye biodegradation ability of bacteria, results in the synergistic effect of the coculture microorganisms.

\section{Introduction}

Effluents from textile industries that contain dyes are highly colored and visually identifiable [1]. The complex aromatic structure of dyes is resistant to light, biological activity, ozone, and other degrading environmental conditions [2]. Fungi have attracted much attention because of their ability to decolorize dyes compared to simple single cell organisms as their increased cell-to-surface ratio provides a greater physical and enzymatic contact condition [3]. They produce ligninmodifying enzymes, such as laccase, manganese peroxidase, and lignin peroxidase, to tolerate the toxicity of dyes and mineralize them [4].

Bacterial contamination is a prevalent problem in fungal dye wastewater decolorization. Critical operational and environmental conditions, including temperature, $\mathrm{pH}$, hydraulic residence time, and sludge residence time [5], are usually controlled to maintain the dominance of fungal biomass [6]. Fulfilling the above control conditions is extremely expensive and unrealistic for practical wastewater treatment.

The present work gives new insight into the synergistic relationship between fungi and bacteria. Fungi and bacteria were cultured together in flasks containing typical reactive dye, and no extra operational and environmental conditions that favor the dominance of fungi were set during the whole experiment. The roles of fungi and bacteria in bioadsorption, biodegradation, total biomass concentration, and settleability were evaluated, and they were significant to the decolorization efficiency of industrial wastewater plant operation. The synergistic effect of fungi and bacteria enhanced their decolorization and settleability, and it gives a novel view on using fungi for textile wastewater treatment. Preventing bacterial contamination or controlling fungi dominance is not the best way to treat textile wastewater.

\section{Materials and Methods}

2.1. Medium. Basal salts medium (BSM) with additional $120 \mathrm{mg} / \mathrm{L}$ of reactive red X-3B (BSM-dye medium) was used. The composition of the BSM media was as described by Juhasz et al. [7]. The reactive red X-3B was purchased from the Dye Synthesis Laboratory of China. The $\mathrm{pH}$ of the medium was adjusted to 7.0, and the temperature was set to $25^{\circ} \mathrm{C}$ during cultivation.

2.2. Enrichment, Isolation, and Identification. A $100 \mathrm{~mL}$ portion of activated sludge sampled from a bioreactor in Jilin 
University was shaken overnight in $100 \mathrm{~mL}$ of Ringer's solution (Dingguo, China) at $30^{\circ} \mathrm{C}$ and $110 \mathrm{rpm}$ in an incubation shaker. BSM $(95 \mathrm{~mL})$ containing $120 \mathrm{mg} / \mathrm{L}$ red reactive $\mathrm{X}$ $3 \mathrm{~B}$ was inoculated with $5 \mathrm{~mL}$ of the supernatant. When the growth of the microorganisms was observed, enrichment was continued by serially subculturing the sample several times in the same medium using a $10 \%$ inoculum from the previous culture.

Initial attempts to separate the resulting fungal-bacterial consortium involved subculturing it into the fresh BSM medium containing $0.1 \mathrm{~g} / \mathrm{L}$ cycloheximide. The absence of fungi was confirmed by plating the subculture onto PDA after each transfer. The resulting bacterial consortium is referred to as the bacteria group hereinafter. To isolate the fungi, the enriched culture was diluted 10 -fold, and $0.1 \mathrm{~mL}$ of the samples was spread onto PDA plates supplemented with $0.06 \mathrm{~g} / \mathrm{L}$ penicillin $\mathrm{G}$ and $0.1 \mathrm{~g} / \mathrm{L}$ streptomycin sulfate. Fungal colonies were selected and replated on the same medium until pure colonies were obtained. The pure colonies were subcultivated on PDA and were identified. A $500 \mu \mathrm{L}$ portion of each colony spore suspension (with $0.2 \mathrm{OD}_{600}$ ) was inoculated into the BSM-dye medium for the subsequent subculturing. This fungal consortium is referred to as the fungi group hereinafter.

The bacterial and fungal samples were obtained through centrifugation (8000 rpm) and washed twice with PBS buffer. Then, DNA extraction, polymerase chain reaction amplification, and denaturing gradient gel electrophoresis (DGGE) analysis of the bacteria/fungi group were consigned to a professional biological engineering company (Sangon Company, Shanghai, China).

2.3. Analysis. Absorbance measurements of the original dye and the decolorized dye by spectrophotometer were performed at $538 \mathrm{~nm}$ to estimate biodegradation occurrence using an ultraviolet-visible (UV-vis) spectrophotometer. Bioadsorption was evaluated using the decolorization efficiencies of the biomass after inactivation by supplementing $0.7 \mathrm{mg} / \mathrm{L} \mathrm{HgSO}_{4}$ in the BSM-dye medium. The decolorization efficiency of the $\mathrm{X}-3 \mathrm{~B}$ was calculated by $\left(1-C / C_{0}\right) \times$ $100 \%$, where $C_{0}$ and $C$ represent the initial and the residual concentrations of $\mathrm{X}-3 \mathrm{~B}$, respectively.

The biomass suspension was collected, and the aggregation index was measured by monitoring the changes in absorbance at $600 \mathrm{~nm}$ using a UV-vis spectrophotometer. The aggregation index $(I \%)$ was calculated using [8] $I(\%)=$ $\left(\left(\mathrm{OD}_{0}-\mathrm{OD}_{30}\right) / \mathrm{OD}_{0}\right) \times 100 \%$, where $\mathrm{OD}_{0}$ and $\mathrm{OD}_{30}$ represent the initial absorbance and the absorbance after $30 \mathrm{~min}$ of deposition, respectively.

All experiments were performed in duplicate, and the average values were used in the calculations.

\section{Results}

3.1. Isolation and Identification. Fungi and bacteria groups were obtained after separation. Two fungi were isolated from the fungi group. The $18 \mathrm{~S}$ rRNA sequences revealed that the sequences were $99 \%$ homologous to those of Geotrichum

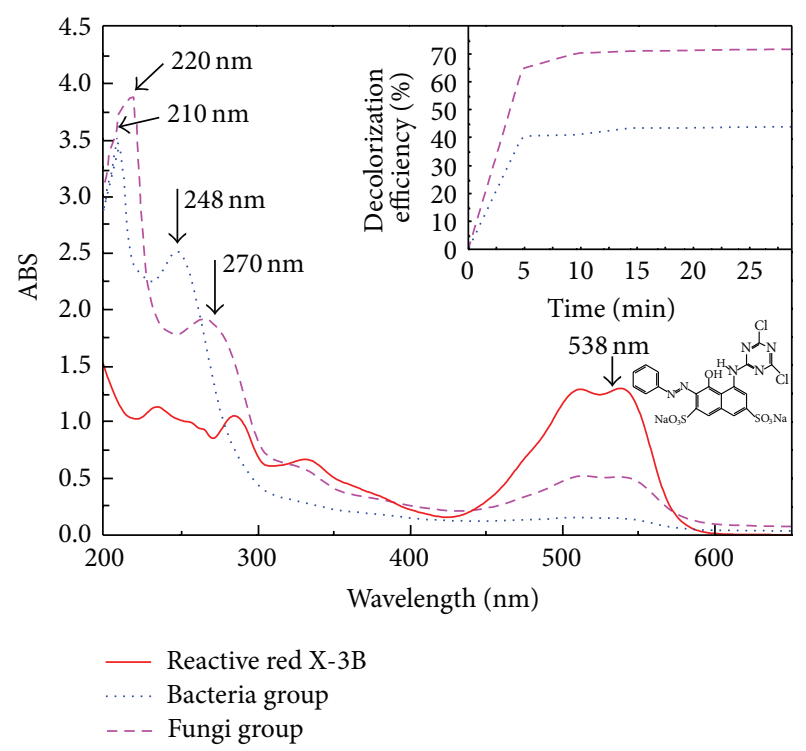

FIGURE 1: UV-vis spectra of the original reactive red X-3B and the residuals after culturing the bacteria and fungi groups in the BSMdye medium for 3 days, respectively; $\mathrm{X}-3 \mathrm{~B}$ adsorption efficiencies of bacteria and fungi groups, respectively (inset).

candidum (Genbank accession number: KJ543497) and Candida pseudolambica (Genbank accession number: KJ543498), respectively. Geotrichum candidum was filamentous under the microscope (Olympus, BX40, Japan) with a Pro-Micro Scan system and the size of the granules was determined using the Scopephoto software. For bacteria identification, the sequences of the 15 dominant bands that appeared in the DGGE profiles were identified and compared with those available in the GenBank library. The majority of the bacterial $16 S$ rDNA sequences were grouped with the members of proteobacteria (9 in total), six of which were in the $\beta$ subdivision. The other bacterial species in the bacteria group were Sphingobacteriia, Flavobacteriia, Bacteroidia, Nitrospirales, and Phycisphaerae.

3.2. Decolorization Mechanisms of the Two Groups. The reactive red X-3B decolorization mechanisms of the fungi group and bacteria group were attributed to both bioadsorption and biodegradation functions, as shown in Figure 1. However, the contributions of bioadsorption and biodegradation in the $\mathrm{X}-3 \mathrm{~B}$ decolorization for the microbial groups were quite different. Bioadsorption, instead of biodegradation, plays a more significant role in fungi group decolorization as it achieved more than $70 \%$ decolorization in $5 \mathrm{~min}$. Such great adsorption capability of fungi is due to their wide range of binding sites for azo dyes [9], that is, amino, carboxyl, phosphate, and hydroxyl functional groups located on the surface of fungi [10]. Using fungi as adsorbing agents has received much attention [11]. However, the removal efficiency of X-3B reached only $44 \%$ when absorption achieved equilibrium at $15 \mathrm{~min}$.

The bacteria group seemed to have complementary advantages over fungi group in terms of bioadsorption and biodegradation. The living bacteria group had stronger 


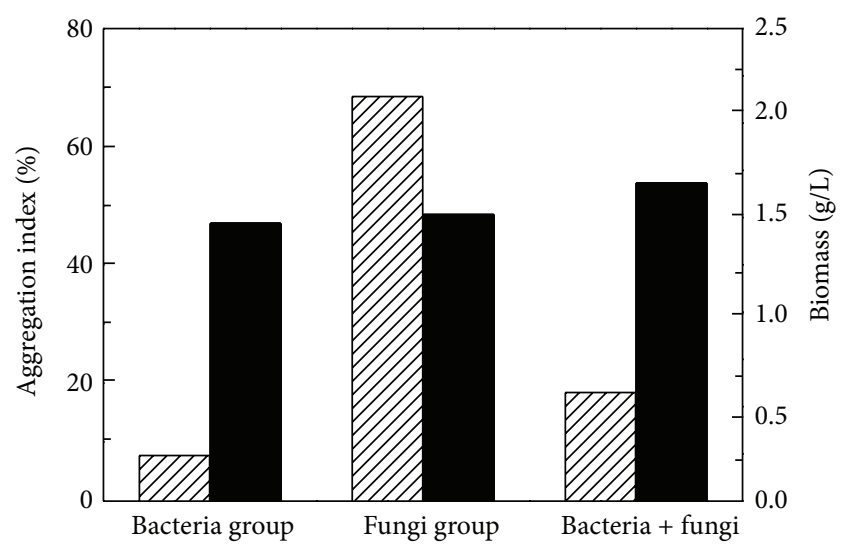

VIZ Aggregation index

Biomass concentration

FIgURE 2: Aggregation indexes and biomass concentrations of the bacteria group, fungi group, and bacteria-fungi coculture at the stationary phase.

biodegradation ability than that of the fungi group (Figure 1). Reactive red X-3B has a maximum absorption peak at $538 \mathrm{~nm}$, and this peak almost disappeared after the bacteria group biodegradation. The new products are found at wavelengths of $210 \mathrm{~nm}$ and $248 \mathrm{~nm}$. The chromogenic group of X3B was broken, and it generated other chromogenic groups. The biodegradation ability of fungus was not as strong as that of bacteria because the peak at the wavelength of $538 \mathrm{~nm}$ was still apparent. The products of the fungus group were different from those of the bacteria group, as confirmed by the shifting of the maximum absorption wavelength from $538 \mathrm{~nm}$ to $220 \mathrm{~nm}$ and $270 \mathrm{~nm}$.

In brief, both bioadsorption and biodegradation decolorized reactive red $\mathrm{X}-3 \mathrm{~B}$ for both the bacteria group and the fungi group. Fungi showed a much better bioadsorption capability and reached equilibrium in $5 \mathrm{~min}$, whereas the bacteria group had a more radical biodegradation for decolorization.

3.3. Settleability Enhancement of the Fungus Group. The aggregation index was used to evaluate the aggregation capability of the microorganisms. At the stationary phase of the microbial groups (the 6th day of culture), the bacteria group had the poorest self-aggregation ability, with an aggregation index of 7.7. The aggregation index of the fungi group was 68.5 , with a very clear boundary between the settled biomass and the supernatant (see Figure 2). Thus, the settleability of the mixed group reached an acceptable degree, with an aggregation index of 18.4. The biomass concentrations of these microbial groups were close. This finding indicates that the aggregation indexes of the groups are comparable and that the competition between bacteria and fungus in the cocultured group does not affect the total biomass. As expected, the fungus enhanced the settleability in the synergistic fungibacteria cocultured group and had no significant influence on the total biomass production.
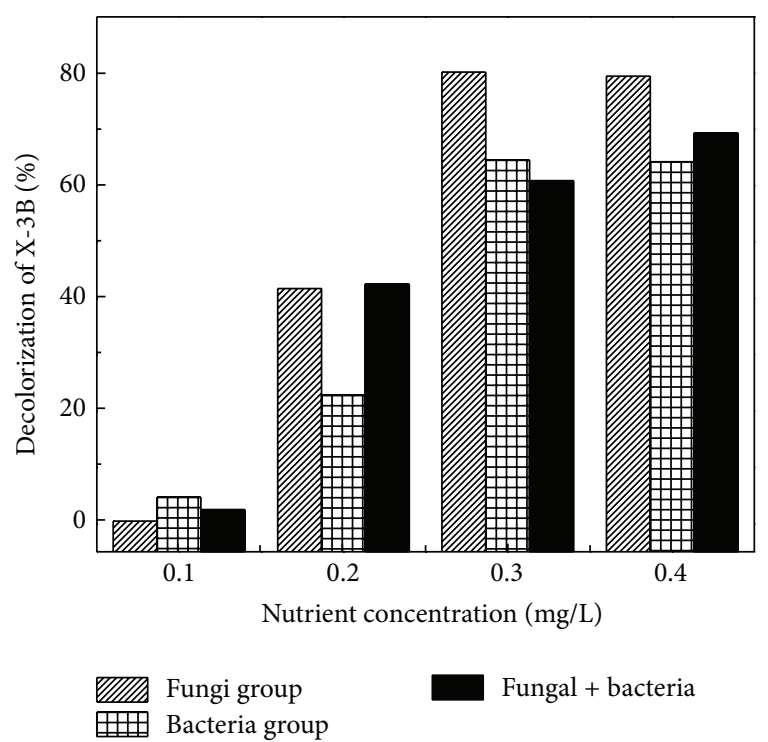

FIGURE 3: Reactive red X-3B decolorization efficiencies at different nutrient levels (each concentration of $\left(\mathrm{NH}_{4}\right)_{2} \mathrm{SO}_{4}, \mathrm{KH}_{2} \mathrm{PO}_{4}$, and $\mathrm{K}_{2} \mathrm{HPO}_{4}$ is $0.1,0.2,0.3$, and $0.4 \mathrm{mg} / \mathrm{L}$ ) for the bacteria group, fungi group, and bacteria-fungi coculture at the stationary phase.

3.4. Decolorization Enhancement of the Bacteria Group. The reactive red $\mathrm{X}-3 \mathrm{~B}$ decolorization efficiencies with different kinds of nutrient (i.e., $\left(\mathrm{NH}_{4}\right)_{2} \mathrm{SO}_{4}, \mathrm{KH}_{2} \mathrm{PO}_{4}$, and $\mathrm{K}_{2} \mathrm{HPO}_{4}$ ) at different levels were determined to identify the decolorization abilities of the individuals and the cocultured bacteria and fungi group (see Figure 3). The influence of nutrient feed levels on decolorization seemed to be generally consistent for the three groups, and the decolorization efficiencies tended to be higher when the nutrient supplications were more abundant. The efficiencies of the three groups with different kinds of nutrient at the same level were very close, and the bacteria group seemed to have a positive effect on the decolorization ability of the cocultured group because of its advanced biodegradation performance (see the UV-vis spectra results in Figure 1).

\section{Discussion}

Traditionally, bacterial proliferation is a problem in nonaseptic fungal decolorization. Bacteria compete with fungi for substrates, and they also deteriorate the dewatering ability [6]. An insight into the synergistic relationship between the fungi group and the bacteria group for azo dye wastewater treatment was given without artificial modification of any operational, environmental, and physiological conditions. These synergistic effects were expressed as both the enhanced settleability of the fungi group and the enhanced biodegradation ability of the bacteria group when the two groups were cocultured. The former is the main contributor to the separation of biomass and effluent, and the latter plays a more important role in the improvement of the quality of the effluent (Figure 4). The fungus in the cocultured group adsorbed the azo dye in several minutes. This adsorption is attributed to the many binding functional groups in their 


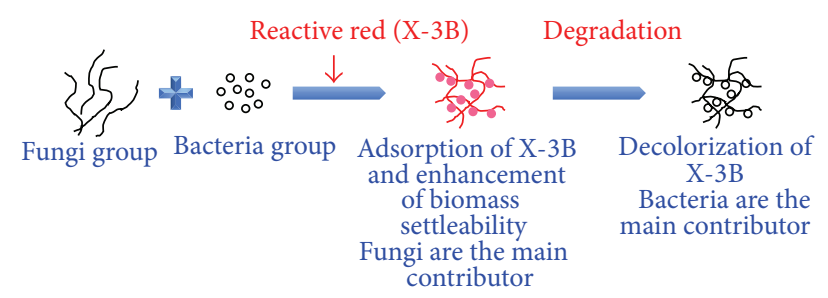

FIGURE 4: Insight into the synergistic effect of fungi and bacteria for reactive red $\mathrm{X}-3 \mathrm{~B}$ decolorization.

cell walls, such as amino, carboxyl, thiol, and phosphate [2]. Then, the azo molecule dye closed around the fungal and bacterial cells that were wrapped together. The dye was easier to transfer into their cells for further biodegradation. The enzyme-mediated activity of fungi enabled the treatment of wastewater containing hazardous or xenobiotic organic pollutants [12]. Thus, the toxicity of the dye dramatically decreased when the bacteria, which presented a much greater growth speed, were added [13].

As discussed above, the synergistic effect of the fungi group and the bacteria group shows that they promoted their own bioaccumulation, bioadsorption, and biodegradation. The relationship between the fungi group and the bacteria group is implied to be not limited to completion, but it could also be a synergistic effect. Therefore, sterilization is not the only way to use fungi for wastewater treatment. The bacteria and fungi groups used in this work were isolated from the same source. The synergistic effect between them was stronger than that from different sources. This process may be an effective way to strengthen the synergistic effect rather than the competition between the two groups.

\section{Conclusions}

Two fungi and 15 bacteria were isolated from activated sludge and were identified and classified into the fungi group and the bacteria group, respectively. Fungi played a more significant role in bioadsorption and settleability, and bacteria were more efficient in reactive red X-3B decolorization when cocultured. The synergistic relationship was implied between the fungi group and the bacteria group for the azo dye wastewater treatment. Therefore, the expensive artificial modification of operational, environmental, and physiological conditions to prevent bacterial contamination is not necessary. The bacteria group and the fungi group used in this work were isolated from the same source. Using cocultured microorganisms from the same source is an effective way to strengthen the synergistic effect.

\section{Conflict of Interests}

The authors declare that there is no conflict of interests regarding the publication of this paper.

\section{Acknowledgments}

The authors are grateful to the financial support from the Natural Sciences Foundation of China (50908096 and 50908097) and the Development Plan Project of Science and Technology of Jilin Province (20140101159JC and 20140101006JC).

\section{References}

[1] N. K. Kiliç, J. L. Nielsen, M. Yüce, and G. Dönmez, "Characterization of a simple bacterial consortium for effective treatment of wastewaters with reactive dyes and $\mathrm{Cr}(\mathrm{VI})$," Chemosphere, vol. 67, no. 4, pp. 826-831, 2007.

[2] P. Kaushik and A. Malik, "Fungal dye decolourization: Recent advances and future potential," Environment International, vol. 35, no. 1, pp. 127-141, 2009.

[3] Z. Aksu and G. Karabayir, "Comparison of biosorption properties of different kinds of fungi for the removal of Gryfalan Black RL metal-complex dye," Bioresource Technology, vol. 99, no. 16, pp. 7730-7741, 2008.

[4] A. Hatakka, "Lignin-modifying enzymes from selected whiterot fungi: production and role in lignin degradation," FEMS Microbiology Reviews, vol. 13, no. 2-3, pp. 125-135, 1994.

[5] R. C. Leitão, A. C. van Haandel, G. Zeeman, and G. Lettinga, "The effects of operational and environmental variations on anaerobic wastewater treatment systems: a review," Bioresource Technology, vol. 97, no. 9, pp. 1105-1118, 2006.

[6] S. Sankaran, S. K. Khanal, N. Jasti, B. Jin, A. L. Pometto, and J. H. Van Leeuwen, "Use of filamentous fungi for wastewater treatment and production of high value fungal byproducts: a review," Critical Reviews in Environmental Science and Technology, vol. 40, no. 5, pp. 400-449, 2010.

[7] A. L. Juhasz, M. L. Britz, and G. A. Stanley, "Degradation of fluoranthene, pyrene, benz[a]anthracene and dibenz[a,h]anthracene by Burkholderia cepacia," Journal of Applied Microbiology, vol. 83, no. 2, pp. 189-198, 1997.

[8] S. S. Adav and D. Lee, "Single-culture aerobic granules with Acinetobacter calcoaceticus," Applied Microbiology and Biotechnology, vol. 78, no. 3, pp. 551-557, 2008.

[9] Y. Fu and T. Viraraghavan, "Removal of Congo Red from an aqueous solution by fungus Aspergillus niger," Advances in Environmental Research, vol. 7, no. 1, pp. 239-247, 2002.

[10] G. Bayramoğlu, G. Çelik, and M. Y. Arica, "Biosorption of Reactive Blue 4 dye by native and treated fungus Phanerocheate chrysosporium: batch and continuous flow system studies," Journal of Hazardous Materials, vol. 137, no. 3, pp. 1689-1697, 2006.

[11] N. S. Maurya, A. K. Mittal, P. Cornel, and E. Rother, "Biosorption of dyes using dead macro fungi: effect of dye structure, ionic strength and pH, Bioresource Technology, vol. 97, no. 3, pp. 512-521, 2006.

[12] D. R. Ryan, W. D. Leukes, and S. G. Burton, "Fungal bioremediation of phenolic wastewaters in an airlift reactor," Biotechnology Progress, vol. 21, no. 4, pp. 1068-1074, 2005.

[13] Y. Liu and Q. Liu, "Causes and control of filamentous growth in aerobic granular sludge sequencing batch reactors," Biotechnology Advances, vol. 24, no. 1, pp. 115-127, 2006. 

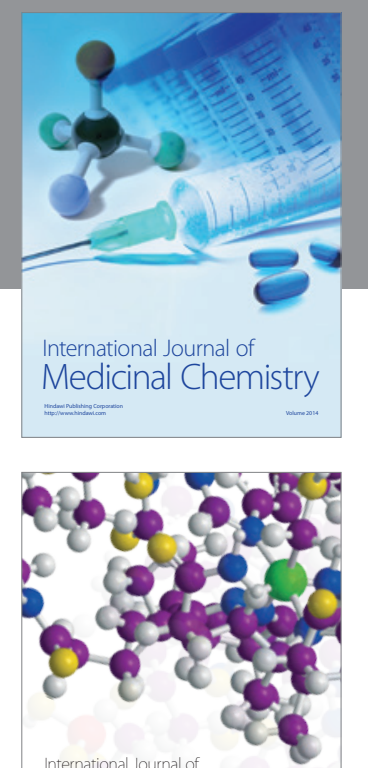

\section{Carbohydrate} Chemistry

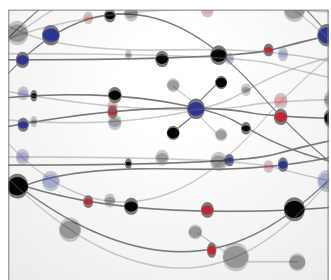

The Scientific World Journal
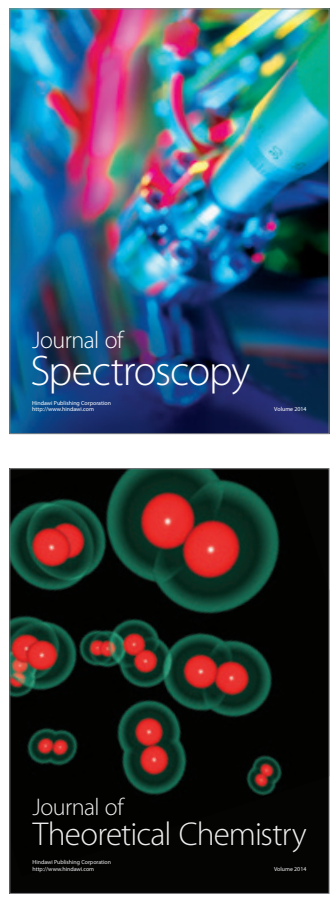
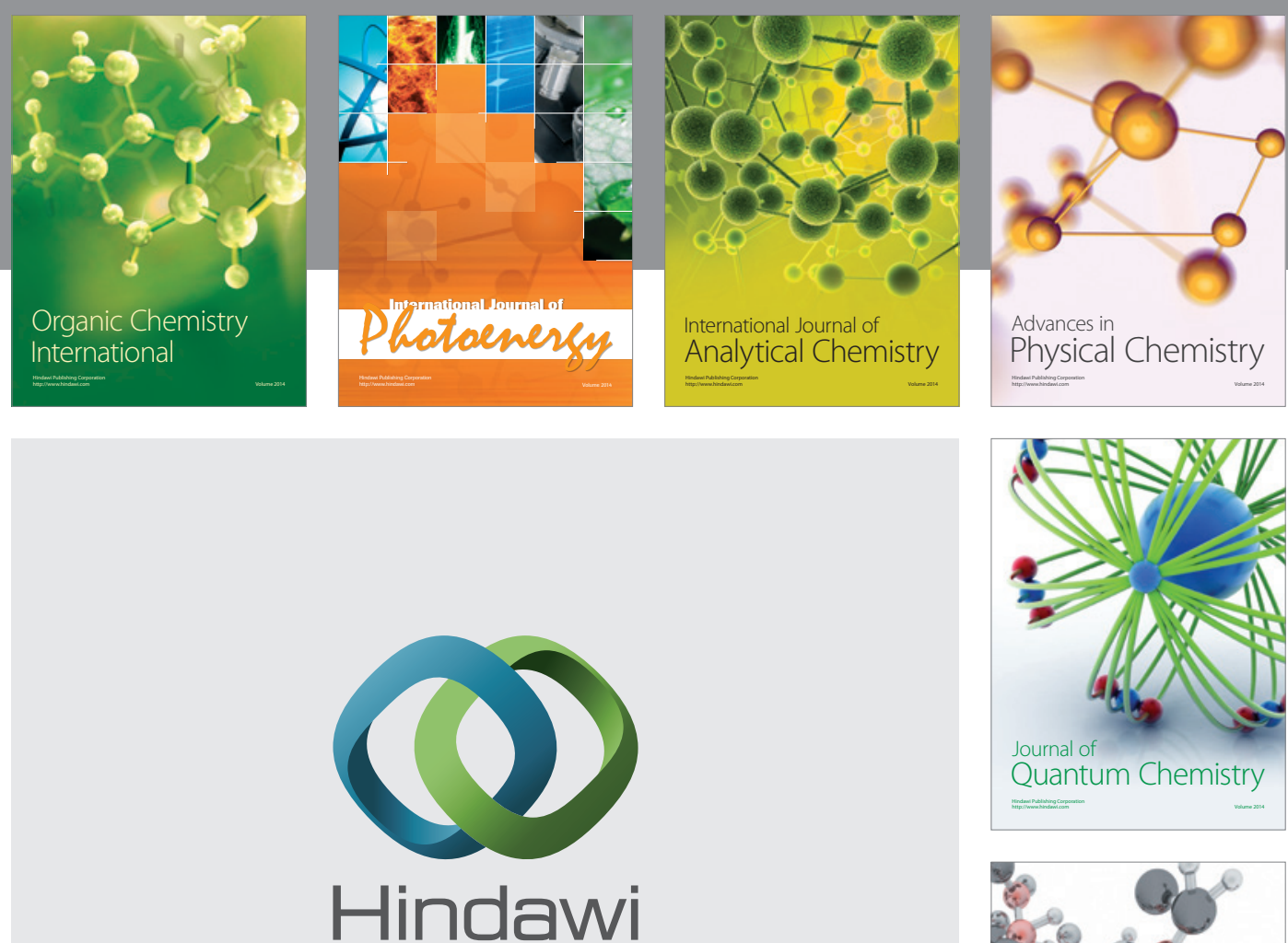

Submit your manuscripts at

http://www.hindawi.com

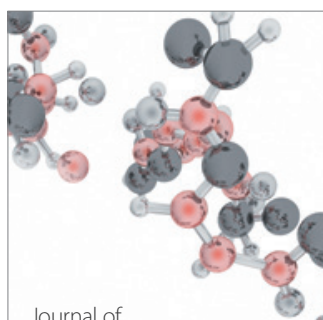

Analytical Methods

in Chemistry

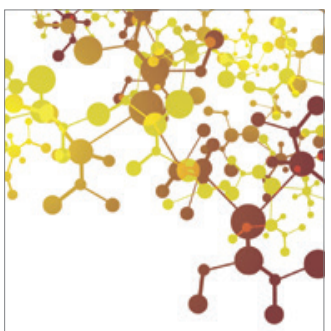

Journal of

Applied Chemistry

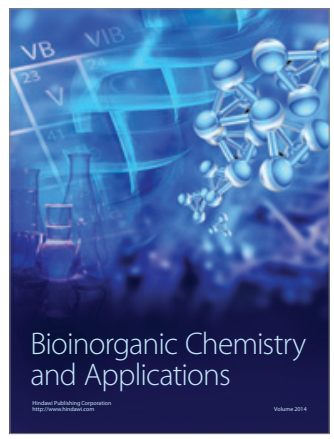

Inorganic Chemistry
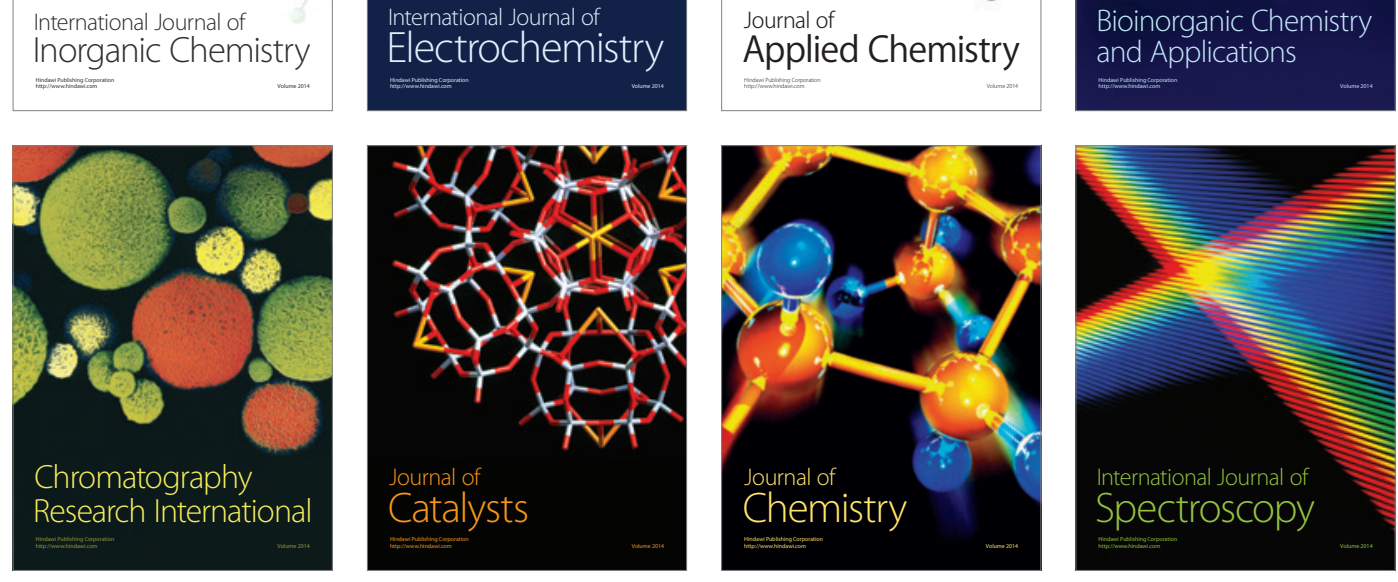